\title{
Spectrophotometric Method for Determination of Five 1,4-Dihydropyridine Drugs Using $N$-Bromosuccinimide and Indigo Carmine Dye
}

\author{
Mohamed A. El Hamd, ${ }^{1}$ Sayed M. Derayea, ${ }^{2}$ Osama H. Abdelmageed, ${ }^{3}$ and Hassan F. Askal ${ }^{4}$ \\ ${ }^{1}$ Department of Pharmaceutical Analytical Chemistry, Faculty of Pharmacy, Al-Azhar University, Assiut 71524, Egypt \\ ${ }^{2}$ Department of Pharmaceutical Analytical Chemistry, Faculty of Pharmacy, Minia University, Minia 61519, Egypt \\ ${ }^{3}$ Department of Pharmaceutical Chemistry, Faculty of Pharmacy, King Abdulaziz University, Jeddah 21589, Saudi Arabia \\ ${ }^{4}$ Department of Pharmaceutical Analytical Chemistry, Faculty of Pharmacy, Assiut University, Assiut 71526, Egypt
}

Correspondence should be addressed to Mohamed A. El Hamd; abo_elhamd2007@yahoo.com

Received 15 March 2013; Revised 10 July 2013; Accepted 17 July 2013

Academic Editor: Hakan Arslan

Copyright (C) 2013 Mohamed A. El Hamd et al. This is an open access article distributed under the Creative Commons Attribution License, which permits unrestricted use, distribution, and reproduction in any medium, provided the original work is properly cited.

\begin{abstract}
Indirect spectrophotometric method is described for quantification of five of 1,4-dihydropyridine (1,4-DHP) drugs using $N$ bromosuccinimide (NBS) with the aid of indigo carmine (INC) dye. The method is based on addition of known excess of NBS to an acidified solution of 1,4-DHP drugs and determining the residual of NBS through its ability to bleach the colour of the used dye; the amount of NBS that reacted corresponded to the amount of drugs. Beer's law is obeyed in the concentration range $1.25-13.00 \mu \mathrm{g} / \mathrm{mL}$. Good correlation coefficients (0.998-0.999) were found between the absorbance values and the corresponding concentrations. Limits of detections ranged from 0.141 to $0.500 \mu \mathrm{g} / \mathrm{mL}$. The proposed method was successfully applied to the analysis of dosage forms; percent of recoveries ranged from 97.31 to $99.46 \%$ without interference from any common excipients. The statistical comparison by Student's $t$-test and variance ratio $F$-test showed no significant difference between the proposed and official or reported methods.
\end{abstract}

\section{Introduction}

1,4-DHP derivatives are vasodilators with a great selectivity for vascular smooth muscles; they are primarily used for treatment of some of cardiovascular diseases such as hypertension, angina, and cardiac arrhythmias. Recently, they were used for the treatment of other pathological states, such as seizures and cerebral ischemic disorders $[1,2]$.

Many analytical methods were developed for determination of 1,4-DHP drugs, namely, nifedipine (NIF), nicardipine (NIC), nimodipine (NIM), felodipine (FEL), and amlodipine (AML) (Figure 1), in their pharmaceutical formulations and in biological fluids, such as titrimetric methods [3, 4], spectrometric methods (spectrophotometry [5-13] or spectrofluorimetry $[12,14-20]$ ), electrochemical methods [21-23], liquid chromatographic methods [24-28], and gas chromatographic methods [29-32].
Classical spectrophotometric measurements and their applications are considered as a routine analytical method in most quality control laboratories. Subsequently, the aim of this study to develop a simple, sensitive, and cost-effective method for determination of these drugs in pure and dosage forms using spectrophotometric technique. The method utilized NBS-INC reagents (Figure 2) and their developed offer the advantage of simplicity, sensitivity, speed, accuracy, and precision without the need for costly equipment/chemicals.

\section{Experimental}

2.1. Instrumentation. Absorbance measurements were made on Shimadzu 1601PC, UV-visible spectrophotometer (Shimadzu, Tokyo, Japan), Jenway 6305, UV-visible spectrophotometer (Jenway LTD, U.K). 
<smiles>CCOC(=O)C1=C(C)NC(C)=C(C(=O)OC)C1c1cccc(Cl)c1Cl</smiles>

FIGURE 1: Chemical structure of the investigated 1,4-DHP drugs.

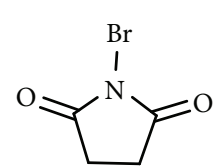

$N$-Bromosuccinimide<smiles>NS(=O)(=O)c1ccc2c(c1)C(=O)/C(=C1\Nc3ccc(S(N)(=O)=O)cc3C1=O)N2</smiles>

Indigo carmine

FIgURE 2: Chemical structure of the chemical reagents.

2.2. Reagents and Solutions. All chemicals, solvents, and reagents were of analytical grade, and their solutions were prepared and diluted in distilled water.

2.2.1. NBS Reagent. NBS reagent (Aldrich Co Ltd., Gillingham-Dorst, Germany) was prepared fresh daily in distilled water as a concentration $0.02 \% \mathrm{w} / \mathrm{v}$.

2.2.2. INC Dye. INC dye (Winlab Co., UK) was prepared fresh daily in distilled water as a concentration $0.07 \% \mathrm{w} / \mathrm{v}$.

2.2.3. Reference Standard of Pure Cited Drugs. Reference standard of pure cited drugs (NIF, atenolol, NIC, NIM, FEL, AML besylate, and metoprolol) was generously supplied by their respective manufacturers in Egypt, without any conflicts of interests in our submitted paper.

Stock of 1,4-DHP standard solutions was prepared fresh daily by dissolving $50 \mathrm{mg}$ of each of them in $2.0 \mathrm{~mL}$ of perchloric acid $(70 \%, 11.6 \mathrm{M})$ using $100 \mathrm{~mL}$ calibrated flask; the contents of the flask were swirled then completed to the volume with diluted aqueous $1.0 \mathrm{M}$ perchloric acid. The working standard solutions were prepared by further dilution with distilled water to obtain the final aliquots concentration.

2.3. Procedure for Calibration Curves. An aliquot of $1.0 \mathrm{~mL}$ of the standard or sample solution was transferred into a $10 \mathrm{~mL}$ calibrated flask. $1.0 \mathrm{~mL}$ of NBS $(0.02 \% \mathrm{w} / \mathrm{v})$ was added and mixed well. The reaction was allowed to proceed for $25 \mathrm{~min}$ at room temperature. $1.0 \mathrm{~mL}$ of INC $(0.07 \% \mathrm{w} / \mathrm{v})$ was added.
The resulting solution was allowed to stand for further $10 \mathrm{~min}$. The solution was diluted to the mark with distilled water, and the absorbance was measured at $607 \mathrm{~nm}$ against a blank experiment treated similarly.

\subsection{General Pretreatment Procedures for Tablets and Capsules}

2.4.1. Pretreatment Procedure for the Assay of Tablet and Capsule Samples. An amount equivalent to $50 \mathrm{mg}$ of active ingredient from 20 finally powdered tablets or 20 mixed capsules was dissolved in $10.0 \mathrm{~mL}$ chloroform in a beaker. The contents of the beaker were swirled, sonicated for about $5 \mathrm{~min}$, then filtered to $100 \mathrm{~mL}$ calibrated flask through a Whatman no. 42 filter paper, and washed with small amount of chloroform. The filtrate was evaporated to dryness, and the residue was dissolved in $2.0 \mathrm{~mL}$ of perchloric acid and then completed to the marke by diluted $1.0 \mathrm{M}$ perchloric acid to give $0.5 \mathrm{mg} / \mathrm{mL}$ of sample solution then the working solutions were treated as mentioned above.

2.4.2. Pretreatment Procedure for the Assay of Tablet and Capsule Samples Containing Two Drugs. 20 tablets (Logimax tablets, containing FEL and metoprolol) or capsules (Tenolat SR capsules, containing NIF and atenolol) were finely powdered. An accurately quantity equivalent to $50 \mathrm{mg}$ of the active ingredient was dissolved in about $10.0 \mathrm{~mL}$ of ethylether, or in $10.0 \mathrm{~mL}$ of chloroform for tablets and capsules in a beaker, respectively. The contents of the beaker were swirled, sonicated for $5 \mathrm{~min}$, and then filtered. The filtrate was evaporated to dryness, and then the procedure was completed as mentioned before.

\section{Results and Discussion}

NBS is an oxidizing agent and perhaps the most important positive bromine containing organic compound, used for spectrophotometric determination of many pharmaceutical compounds [33-35]. A close examination of the literature search presented in the introduction reveals that NBS has not yet been used for the spectrophotometric determination 


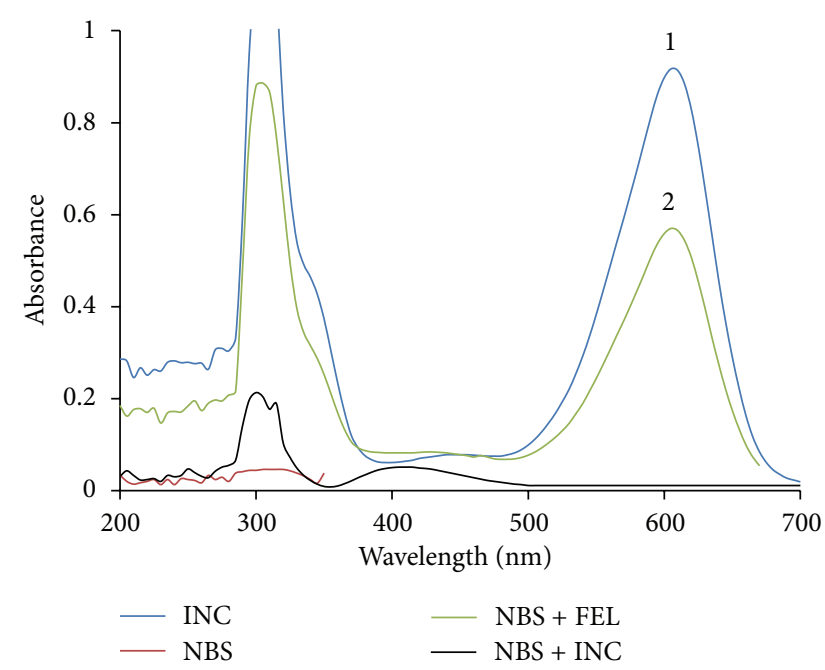

FIGURE 3: Absorption spectra of $0.07 \% \mathrm{w} / \mathrm{v}$ INC (1) in the absence and (2) in the presence of $0.2 \% \mathrm{w} / \mathrm{v}$ NBS with FEL, $7.0 \mu \mathrm{g} / \mathrm{mL}$.

of these drugs. The present work involves the bromination of the investigated drugs by NBS followed by determination of surplus NBS after allowing the bromination reaction to complete. The unreacted NBS is determined by reacting with a fixed amount of INC dye and measured at $607 \mathrm{~nm}$, (Figure 3) using FEL as a representative example.

\subsection{Optimization of the Reaction Variables}

3.1.1. Reagent Concentration. A preliminary experiments were performed to determine the optimal concentration of NBS and INC dye. According to the above-mentioned reactions, NBS solution should be added in excess to react with the investigated drugs. By measuring the excess reagent, the consumed reagent would correspond to the amount of the drug. The highest concentration of each reagent, which gives the highest absorption value within the practical sensitivity range of absorption values $(\approx 0.9)$, was found to be $0.02 \%$ and $0.07 \% \mathrm{w} / \mathrm{v}$ for NBS and INC, respectively.

3.1.2. Type and Concentration of the Acid. Perchloric acid was found to be the desirable medium for bromination of the investigated drugs by NBS; additionally it contributed in drugs solubility and also increased NBS potential for INC oxidation.

3.1.3. Reaction Time and the Reaction Product Stability. For a quantitative reaction between the investigated drugs and NBS, contact time of $20 \mathrm{~min}$ was found necessary in the proposed method, and constant absorbance readings were obtained when contact times were extended up to $45 \mathrm{~min}$ (Figure 4). Another standing time for $10 \mathrm{~min}$ was necessary for the bleaching of the dye colour by the residual NBS. The measured colour was found to be stable for several hours in the presence of the reaction products.

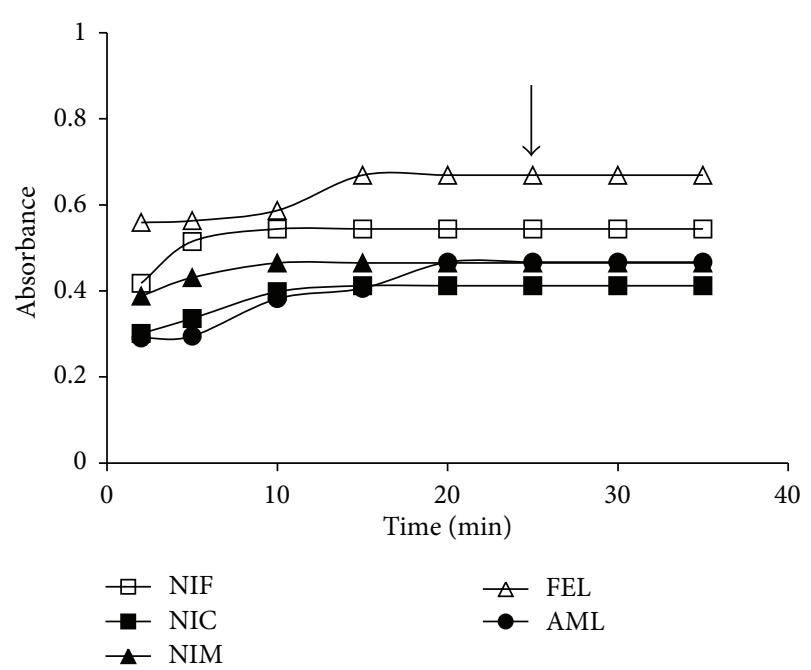

FIGURE 4: Effect of time on the reaction between drugs, $7 \mu \mathrm{g} / \mathrm{mL}$ and NBS/INC.

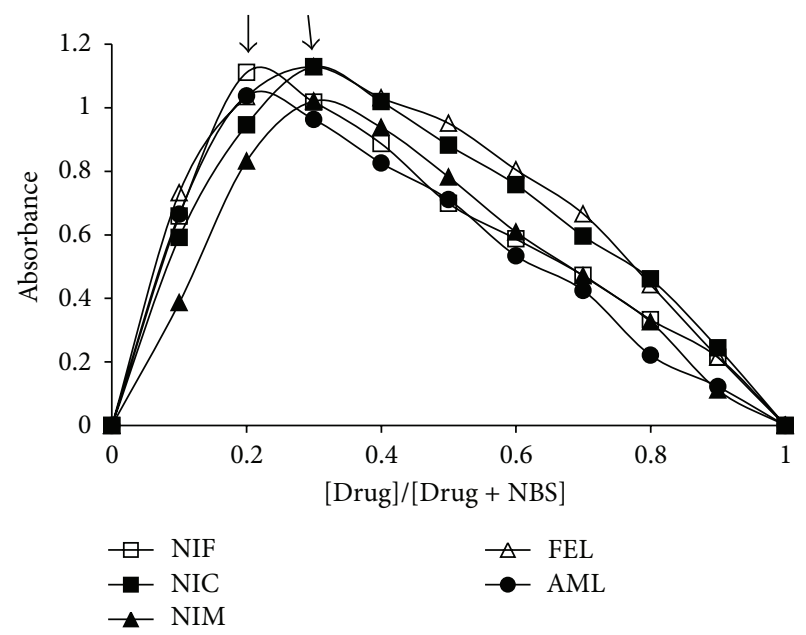

FIGURE 5: Molar ratios of NBS and investigated drugs.

\subsection{Reaction Stoichiometry and Suggested Mechanisms}

3.2.1. Reaction Stoichiometry. Job's method of continuous variation [36] was employed to establish the stoichiometry of the reaction; master equimolar solutions $1.5 \times 10^{-3} \mathrm{M}$ for both NBS ( $\approx 0.02 \%$, w/v, fixed system between NBS and INC) and the drugs were prepared. Series of $10.0 \mathrm{~mL}$ portions of the master solutions were made up involving different complimentary proportions $(0.00: 0.10,0.10: 0.90, \ldots, 0.90: 0.10$, $0.10: 0.00)$ using $10 \mathrm{~mL}$ volumetric flasks, mixed well, and then subjected to the recommended procedure.

The results which we obtained revealed that the ratio between NBS and NIF or AML was 1:4. The ratio between NBS and NIC or NIM or FEL was 1:2 (Figure 5).

3.2.2. Suggested Reaction Mechanism between the Studied Drugs and NBS. A suggested bromination reaction between 


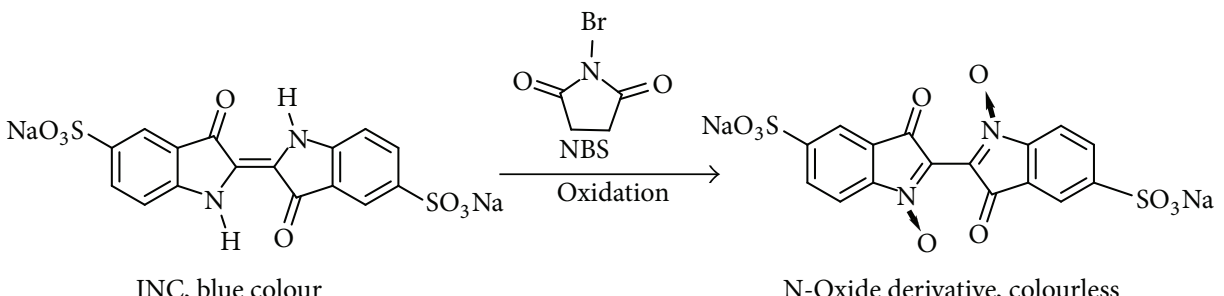

INC, blue colour

N-Oxide derivative, colourless

SCHEME 1: Suggested reaction mechanism between INC and NBS.

TABLE 1: Quantitative parameters and statistical data for determination of the studied drugs using NBS/INC method.

\begin{tabular}{lccccccc}
\hline Drug & $\begin{array}{c}\text { Linear range } \\
(\mu \mathrm{g} / \mathrm{mL})\end{array}$ & Intercept $\pm \mathrm{SD}^{1}$ & Slope $\pm \mathrm{SD}^{1}$ & $r$ & $\begin{array}{c}\varepsilon \times 10^{4} \\
\left(\mathrm{~L} \mathrm{~mol}^{-1} \mathrm{~cm}^{-1}\right)\end{array}$ & LOD $(\mu \mathrm{g} / \mathrm{mL})$ & $\mathrm{LOQ}(\mu \mathrm{g} / \mathrm{mL})$ \\
\hline NIF & $1.25-12.00$ & $0.041 \pm 0.008$ & $0.067 \pm 0.001$ & 0.998 & 2.511 & 0.376 & 0.498 \\
NIC & $1.50-13.00$ & $0.003 \pm 0.009$ & $0.056 \pm 0.001$ & 0.997 & 2.945 & 0.500 & 1.253 \\
NIM & $1.50-13.00$ & $0.070 \pm 0.010$ & $0.060 \pm 0.001$ & 0.997 & 2.746 & 3.914 & 0.141 \\
FEL & $1.25-10.00$ & $0.076 \pm 0.004$ & $0.085 \pm 0.001$ & 0.999 & 3.728 & 0.203 & 0.470 \\
AML & $1.50-13.00$ & $0.046 \pm 0.004$ & $0.059 \pm 0.001$ & 0.999 & & 0.677 \\
\hline
\end{tabular}

${ }^{1}$ Mean of three determinations.

TABLE 2: Assay of five replicate samples of the studied drugs by NBS/INC method at one concentration level.

\begin{tabular}{|c|c|c|c|c|c|c|c|c|}
\hline \multirow{2}{*}{ Drug } & \multirow{2}{*}{ Conc. $(\mu \mathrm{g} / \mathrm{mL})$} & \multicolumn{5}{|c|}{ Absorbance } & \multirow{2}{*}{ Mean \pm SD } & \multirow{2}{*}{ RSD } \\
\hline & & 1 & 2 & 3 & 4 & 5 & & \\
\hline NIF & 7.50 & 0.587 & 0.582 & 0.589 & 0.583 & 0.586 & $0.585 \pm 0.003$ & $\overline{0.440}$ \\
\hline NIC & 10.0 & 0.611 & 0.613 & 0.612 & 0.615 & 0.617 & $0.614 \pm 0.002$ & 0.351 \\
\hline NIM & 8.00 & 0.548 & 0.546 & 0.547 & 0.551 & 0.549 & $0.548 \pm 0.001$ & 0.314 \\
\hline FEL & 5.00 & 0.521 & 0.525 & 0.523 & 0.528 & 0.526 & $0.525 \pm 0.002$ & 0.461 \\
\hline AML & 8.00 & 0.527 & 0.533 & 0.531 & 0.529 & 0.532 & $0.530 \pm 0.003$ & 0.406 \\
\hline
\end{tabular}

some of the studied drugs and bromate/bromide mixture was reported previously in $[3,4]$. In the proposed method NBS was used as a safe brominating reagent; on the other hand the proposed method was carried out using $N$-chlorosuccinamide (NCS) reagent (Aldrich Co., Ltd., Gillingham-Dorst, Germany), which has nearly the same oxidation potential as NBS. The results revealed that NCS incapable to react with the studied drugs through an oxidation reaction that indicate the reaction pathway is a bromination rather than oxidation.

3.2.3. Suggested Reaction Mechanism between INC and NBS. INC has a blue colour in aqueous solution showed $\lambda_{\max }$ at $607 \mathrm{~nm}$ due to its highly conjugated structure (Figure 2) and NBS in acid medium has an oxidation power sufficient to oxidize INC to give colourless $\mathrm{N}$-oxide derivative, the suggested mechanism is given in Scheme 1.

3.3. Validation of Proposed Methods. The developed method was fully validated according to USP XXVI [39] validation guidelines and International Conference on Harmonization (ICH) [40] guidelines.

3.3.1. Linearity Range, Detection, and Quantification Limits. Under the specified optimum reaction conditions, the calibration curves for the investigated drugs were constructed by analyzing a series of different concentrations of the standard solutions.

Linear relationships were found between the absorbance intensities and the concentrations of drugs, as indicated by the high correlation coefficients $(r)$ which are obtained (0.998-0.999), in the concentration range of 1.25$13.00 \mu \mathrm{g} / \mathrm{mL}$. The limits of detection (LOD) and limits of quantitation (LOQ) were determined according to the IUPAC definitions [41] using the formula LOD or LOQ = $\kappa \mathrm{SD}_{a / b}$, where $\kappa=3$ for LOD and 10 for $\mathrm{LOQ}, \mathrm{SD}_{a}$ is the standard deviation of the intercept, and $b$ is the slope. The regression equations for the results were derived using the least square method; the obtained results were summarized in Table 1.

3.3.2. Precision. The precision of the proposed method was determined by carrying out replicate analysis of five separate sample solutions at one concentration level. The relative standard deviations (RSD) did not exceed $2 \%$, indicating the good repeatability of the proposed method, Table 2 .

The interday precision was assessed by analyzing the same sample, as triplicate, in five separate days.

3.3.3. Robustness and Ruggedness. Robustness was examined by evaluating the influence of small variation in some experimental parameters on the method's suitability and specificity. 
TABLE 3: Robustness studies for NBS/INC method.

\begin{tabular}{|c|c|c|c|c|c|}
\hline \multirow{2}{*}{ Variation } & \multicolumn{5}{|c|}{ Recovery $\% \pm \mathrm{SD}^{\mathrm{a}}$} \\
\hline & $\mathrm{NIF}^{\mathrm{b}}$ & $\mathrm{NIC}^{\mathrm{b}}$ & NIM $^{\mathrm{b}}$ & FEL $^{\mathrm{b}}$ & $\mathrm{AML}^{\mathrm{b}}$ \\
\hline No variation & $99.41 \pm 0.65$ & $97.22 \pm 1.07$ & $99.80 \pm 0.33$ & $99.71 \pm 1.16$ & $99.80 \pm 0.23$ \\
\hline \multicolumn{6}{|l|}{ NBS conc. } \\
\hline $0.019 \% \mathrm{w} / \mathrm{v}$ & $99.32 \pm 0.36$ & $97.82 \pm 0.38$ & $97.82 \pm 0.79$ & $99.62 \pm 0.54$ & $97.44 \pm 0.34$ \\
\hline $0.021 \% \mathrm{w} / \mathrm{v}$ & $97.25 \pm 0.63$ & $99.38 \pm 0.53$ & $99.55 \pm 0.74$ & $98.55 \pm 0.63$ & $99.26 \pm 0.22$ \\
\hline \multicolumn{6}{|l|}{ INC conc. } \\
\hline $0.069 \% \mathrm{w} / \mathrm{v}$ & $97.90 \pm 1.75$ & $99.30 \pm 0.67$ & $99.67 \pm 0.78$ & $97.71 \pm 0.89$ & $98.71 \pm 1.33$ \\
\hline $0.071 \% \mathrm{w} / \mathrm{v}$ & $98.15 \pm 0.95$ & $97.18 \pm 0.15$ & $99.82 \pm 0.39$ & $98.27 \pm 0.29$ & $99.10 \pm 0.28$ \\
\hline \multicolumn{6}{|c|}{ Reaction time of NBS } \\
\hline \multicolumn{6}{|c|}{ With INC } \\
\hline $9 \mathrm{~min}$ & $98.16 \pm 0.69$ & $99.15 \pm 0.16$ & $97.41 \pm 0.38$ & $98.77 \pm 0.19$ & $99.92 \pm 0.19$ \\
\hline $11 \mathrm{~min}$ & $99.20 \pm 1.05$ & $98.44 \pm 0.67$ & $98.56 \pm 0.86$ & $97.21 \pm 0.98$ & $100.22 \pm 1.05$ \\
\hline \multicolumn{6}{|l|}{ With drug } \\
\hline $24 \mathrm{~min}$ & $99.73 \pm 0.72$ & $99.70 \pm 1.38$ & $98.28 \pm 1.02$ & $100.26 \pm 1.15$ & $97.78 \pm 0.15$ \\
\hline $26 \mathrm{~min}$ & $98.12 \pm 0.98$ & $97.51 \pm 1.15$ & $99.21 \pm 0.73$ & $99.71 \pm 0.65$ & $98.74 \pm 1.65$ \\
\hline
\end{tabular}

${ }^{a}$ Mean of three determinations.

${ }^{\mathrm{b}}$ Drugs concentration $10.0 \mu \mathrm{g} / \mathrm{mL}$.

TABLE 4: Ruggedness studies for NBS/INC method.

\begin{tabular}{|c|c|c|c|c|c|}
\hline \multirow{3}{*}{ Drugs $^{\mathrm{b}}$} & \multicolumn{5}{|c|}{ Recovery $\% \pm S^{a}$} \\
\hline & \multicolumn{2}{|c|}{ Instrument } & \multicolumn{3}{|c|}{ Interday variation } \\
\hline & Shimadzu & Jenway & Day 1 & Day 2 & Day 3 \\
\hline NIF & $99.72 \pm 0.85$ & $98.90 \pm 0.64$ & $100.10 \pm 0.85$ & $100.31 \pm 0.68$ & $99.51 \pm 1.30$ \\
\hline NIC & $100.31 \pm 0.78$ & $99.37 \pm 0.69$ & $98.51 \pm 0.82$ & $99.20 \pm 1.02$ & $99.74 \pm 0.65$ \\
\hline NIM & $101.81 \pm 0.82$ & $100.62 \pm 1.15$ & $100.20 \pm 1.06$ & $99.80 \pm 0.75$ & $100.26 \pm 0.60$ \\
\hline FEL & $99.40 \pm 0.96$ & $100.21 \pm 1.18$ & $101.50 \pm 0.51$ & $100.42 \pm 1.40$ & $99.80 \pm 1.04$ \\
\hline AML & $100.30 \pm 1.32$ & $99.80 \pm 0.76$ & $99.52 \pm 0.97$ & $100.68 \pm 0.59$ & $99.60 \pm 1.15$ \\
\hline
\end{tabular}

${ }^{\mathrm{a}}$ Mean of three determinations.

${ }^{\mathrm{b}}$ Concentration of the drugs is $10.0 \mu \mathrm{g} / \mathrm{mL}$.

TABLE 5: Application NBS/INC method for 1,4-DHP drugs' tablets and capsules.

\begin{tabular}{|c|c|c|c|c|}
\hline \multirow{2}{*}{ Product } & \multicolumn{2}{|c|}{ Recovery $\% \pm \mathrm{SD}^{\mathrm{a}}$} & \multirow{2}{*}{$F$-value ${ }^{\mathrm{b}}$} & \multirow{2}{*}{$t$-value ${ }^{\mathrm{b}}$} \\
\hline & Proposed method & Official or reported method ${ }^{c}$ & & \\
\hline Epilate capsules & $98.62 \pm 0.05$ & $99.52 \pm 0.11$ & 0.20 & 1.54 \\
\hline Epilate retard tablets & $99.21 \pm 0.04$ & $98.51 \pm 0.13$ & 0.10 & 1.63 \\
\hline Tenolat SR capsules* & $100.33 \pm 0.85$ & $100.52 \pm 0.66$ & 2.00 & 1.11 \\
\hline$\left(_{\text {Pelcard SR capsules })^{c}}\right.$ & $97.31 \pm 0.47$ & $99.74 \pm 0.11$ & 0.05 & 2.00 \\
\hline Nimotop tablets & $99.46 \pm 0.20$ & $98.61 \pm 0.19$ & 0.25 & 1.82 \\
\hline Plendil tablets & $99.24 \pm 0.07$ & $99.24 \pm 0.13$ & 0.82 & 0.41 \\
\hline Plentopine tablets & $98.39 \pm 0.13$ & $99.22 \pm 0.11$ & 0.72 & 1.86 \\
\hline Logimax tablets* & $99.22 \pm 0.15$ & $99.34 \pm 0.17$ & 0.10 & 0.24 \\
\hline (Alkapress tablets) $^{\mathrm{c}}$ & $99.34 \pm 0.10$ & $99.21 \pm 0.12$ & 0.17 & 0.17 \\
\hline (Myodura tablets) $^{\mathrm{c}}$ & $99.26 \pm 0.05$ & $98.31 \pm 0.11$ & 0.21 & 1.45 \\
\hline (Amlodipine tablets) $^{\mathrm{c}}$ & $98.38 \pm 0.04$ & $97.20 \pm 0.12$ & 0.11 & 1.85 \\
\hline$(\text { Regcor tablets })^{c}$ & $98.43 \pm 0.11$ & $99.24 \pm 0.16$ & 0.47 & 0.47 \\
\hline (Vasonorm tablets) $^{\mathrm{c}}$ & $97.72 \pm 0.11$ & $98.41 \pm 0.19$ & 2.44 & 0.54 \\
\hline
\end{tabular}

${ }^{\mathrm{a}}$ Mean of five determinations.

${ }^{\mathrm{b}}$ Theoretical values for $F$ and $t$ at $95 \%$ confidence limit $(n=5)$ were 6.39 and 2.78, respectively.

${ }^{c}$ Reported methods [37, 38].

* Tablets and capsules that contain two drugs. 
The changed parameters were the concentration of analytical reagents and the reaction time. In these experiments, one parameter was changed whereas the other was kept unchanged, and the recovery percentages were calculated each time. The obtained results revealed that none of these variables significantly affect the original data of the proposed method (Table 3).

Ruggedness for the proposed method was tested by applying the assay of the investigated drugs using the same experimental conditions with other different instrument at two different laboratories and different elapsed time. The results obtained were found to be reproducible, as RSD did not exceed $2 \%$ (Table 4 ).

3.3.4. Accuracy and Analysis of Tablets and Capsules. Different pharmaceutical formulations including tablets and capsules were analysed for their contents of 1,4-DHP drugs by the proposed, official $[42,43]$ and reported methods $[37,38]$ (Table 5). The results which are obtained from the proposed method were compared with those obtained from either official or reported methods with respect to the accuracy $(t-$ test) and precision ( $F$-test). No significant differences were found between the calculated and theoretical values of $t$ - and $F$-tests at 95\% confidence level proving similar accuracy and precision in the analysis of the investigated drugs in their dosage forms as in pure form.

\section{Conclusion}

In this work a validated method was described; all the analytical reagents used are safe, inexpensive, have good shelf life and available in the most analytical laboratories. Interferences from other co-formulated drugs and common excipients can be eliminated by a simple one-step extraction procedure.

\section{References}

[1] Y. Ikegaya, N. Nishiyama, and N. Matsuki, "L-type Ca ${ }^{2+}$ channel blocker inhibits mossy fiber sprouting and cognitive deficits following pilocarpine seizures in immature mice," Neuroscience, vol. 98, no. 4, pp. 647-659, 2000.

[2] Y. Murai, H. Uneyama, H. Ishibashi, K. Takahama, and N. Akaike, "Preferential inhibition of L- and N-type calcium channels in the rat hippocampal neurons by cilnidipine," Brain Research, vol. 854, no. 1-2, pp. 6-10, 2000.

[3] B. Kanakapura, C. Umakanthappa, and N. Paregowda, "Titrimetric and spectrophotometric assay of felodipine in tablets using bromate-bromide, Methyl Orange and Indigo Carmine reagents," Journal of the Serbian Chemical Society, vol. 70, no. 7, pp. 969-978, 2005.

[4] B. Kanakapura, C. Umakanthappa, and N. Paregowda, "Titrimetric and modified spectrophotometric methods for the determination of amlodipine besylate using bromate-bromide mixture and two dyes," ScienceAsia, vol. 32, no. 3, pp. 271-278, 2006.

[5] M. Nasr-Esfahani, M. Moghadam, and G. Valipour, "Rapid and efficient aromatization of Hantzsch 1,4-dihydropyridines with potassium peroxomonosulfate catalyzed by manganese(III)
Schiff base complexes," Journal of the Iranian Chemical Society, vol. 5, no. 2, pp. 244-251, 2008.

[6] S. B. Wankhede, K. C. Raka, S. B. Wadkar, and S. S. Chitlange, "Spectrophotometric and HPLC methods for simultaneous estimation of amlodipine besilate, losartan potassium and hydrochlorothiazide in tablets," Indian Journal of Pharmaceutical Sciences, vol. 72, no. 1, pp. 136-140, 2010.

[7] M. A. Rontogianni, C. K. Markopoulou, and J. E. Koundourellis, "HPLC and chemometrically-assisted spectrophotometric estimation of two binary mixtures for combined hypertension therapy," Journal of Liquid Chromatography and Related Technologies, vol. 29, no. 18, pp. 2701-2719, 2006.

[8] N. Rahman and S. N. Hejaz Azmi, "New spectrophotometric methods for the determination of nifedipine in pharmaceutical formulations," Acta Biochimica Polonica, vol. 52, no. 4, pp. 915922, 2005.

[9] N. Rahman and S. N. H. Azmi, "Validated spectrophotometric method for the assay of nifediplne in bulk and commercial dosage forms," ScienceAsia, vol. 32, no. 4, pp. 429-435, 2006.

[10] B. Kanakapura, C. Umakanthappa, and N. Paregowda, "Spectrophotometric and high performance liquid chromatographic determination of amlodipine besylate in pharmaceuticals," ScienceAsia, vol. 31, pp. 13-21, 2005.

[11] K. R. Mahadik, G. B. Byale, H. N. More, and S. S. Kadam, "Spectrophotometric estimation of nifedipine and its formulation," East-Pharm, pp. 34121-34122, 1991.

[12] H. F. Askal, O. H. Abdelmageed, S. M. S. Ali, and M. A. El Hamd, "Spectrophotometric and spectrofluorimetric determination of 1, 4- dihydropyridine drugs using potassium permanganate and cerium (iv) ammonium sulphate," Bulletin of Pharmaceutical Sciences, vol. 33, no. 2, pp. 201-215, 2010.

[13] M. A. El Hamd, S. M. Derayea, O. H. Abdelmageed, and H. F. Askal, "A novel spectrophotometric method for determination of five 1, 4-dihydropyridine drugs in their tablets and capsules using vanillin reagent," The American Journal of Analytical Chemistry, vol. 4, pp. 148-156, 2013.

[14] H. H. Abdine, "Spectrofluorimetric determination of amlodipine," Mansoura Journal of Pharmaceutical Sciences, vol. 25, no. 1, pp. 31-38, 2009.

[15] A. B. Tabrizi, "A new spectrofluorimetric method for determination of nifedipine in pharmaceutical formulations," Chemia Analityczna, vol. 52, no. 4, pp. 635-643, 2007.

[16] M. I. Walash, F. Belal, N. El-Enany, and A. A. Abdelal, "Kinetic spectrofluorometric determination of certain calcium channel blockers via oxidation with cerium (IV) in pharmaceutical preparations," International Journal of Biomedical Science, vol. 5, no. 2, pp. 146-157, 2009.

[17] F. Belal, A. A. Al-Majed, S. Julkhuf, and N. Y. Khalil, "Spectrofluorometric determination of nimodipine in dosage forms and human urine," Pharmazie, vol. 58, no. 12, pp. 874-876, 2003.

[18] S. M. Al-Ghannam and A. M. Al-Olyan, "Spectrofluorometric determination of nicardipine, nifedipine and isradipine in pharmaceutical preparations and biological fluids," Central European Journal of Chemistry, vol. 6, no. 2, pp. 222-228, 2008.

[19] H. M. Abdel-Wadood, N. A. Mohamed, and A. M. Mahmoud, "Validated spectrofluorometric methods for determination of amlodipine besylate in tablets," Spectrochimica Acta A, vol. 70, no. 3, pp. 564-570, 2008.

[20] S. M. Derayea, H. F. Askal, O. H. Abdelmageed, and M. A. El Hamd, "Spectrophotometric determination of amlodipine and nicardipine in pharmaceutical formulations via binary complex 
formation with eosin Y," Journal of Applied Pharmaceutical Science, vol. 2, no. 6, pp. 84-89, 2012.

[21] R. J. B. Diez-Caballero, L. L. de la Torre, J. F. A. Valentin, and A. A. Garcia, "Adsorptive stripping voltammetry for the determination of nifedipine in human serum," Talanta, vol. 36, no. 4, pp. 501-504, 1989.

[22] M. M. Ghoneim, A. Tawfik, and P. Y. Khashaba, "Cathodic adsorptive stripping square-wave voltammetric determination of nifedipine drug in bulk, pharmaceutical formulation and human serum," Analytical and Bioanalytical Chemistry, vol. 375, no. 3, pp. 369-375, 2003.

[23] N. Özaltin, C. Yardimci, and I. Süslü, "Determination of nifedipine in human plasma by square wave adsorptive stripping voltammetry," Journal of Pharmaceutical and Biomedical Analysis, vol. 30, no. 3, pp. 573-582, 2002.

[24] M. V. Vertzoni, C. Reppas, and H. A. Archontaki, "Sensitive and simple liquid chromatographic method with ultraviolet detection for the determination of nifedipine in canine plasma," Analytica Chimica Acta, vol. 573-574, pp. 298-304, 2006.

[25] X.-D. Wang, J.-L. Li, Y. Lu et al., "Rapid and simultaneous determination of nifedipine and dehydronifedipine in human plasma by liquid chromatography-tandem mass spectrometry: application to a clinical herb-drug interaction study," Journal of Chromatography B, vol. 852, no. 1-2, pp. 534-544, 2007.

[26] H. S. Abou-Auda, T. A. Najjar, K. I. Al-Khamis, B. M. Al-Hadiya, N. M. Ghilzai, and N. F. Al-Fawzan, "Liquid chromatographic assay of nifedipine in human plasma and its application to pharmacokinetic studies," Journal of Pharmaceutical and Biomedical Analysis, vol. 22, no. 2, pp. 241-249, 2000.

[27] A.-E. F. Nassar, "Online hydrogen-deuterium exchange and a tandem-quadrupole time-of-flight mass spectrometer coupled with liquid chromatography for metabolite identification in drug metabolism," Journal of Chromatographic Science, vol. 41, no. 8, pp. 398-404, 2003.

[28] L. H. Migliorança, R. E. Barrientos-Astigarraga, B. S. Schug, H. H. Blume, A. S. Pereira, and G. De Nucci, "Felodipine quantification in human plasma by high-performance liquid chromatography coupled to tandem mass spectrometry," Journal of Chromatography B, vol. 814, no. 2, pp. 217-223, 2005.

[29] M. T. Rosseel and M. G. Bogaert, "Determination of nifedipine in human plasma by capillary gas chromatography with nitrogen detection," Journal of Chromatography, vol. 279, pp. 675680, 1983

[30] J. Martens, P. Banditt, and F. P. Meyer, "Determination of nifedipine in human serum by gas chromatography-mass spectrometry: validation of the method and its use in bioavailability studies," Journal of Chromatography B, vol. 660, no. 2, pp. 297302, 1994.

[31] A. T. Wu, I. J. Massey, and S. Kushinsky, "Capillary column gas chromatographic method using electron-capture detection for the simultaneous determination of nicardipine and its pyridine metabolite II in plasma," Journal of Chromatography B, vol. 59, no. 1, pp. 65-73, 1987.

[32] R. Nishioka, I. Umeda, N. Oi, S. Tabata, and K. Uno, "Determination of felodipine and its metabolites in plasma using capillary gas chromatography with electron-capture detection and their identification by gas chromatography-mass spectrometry," Journal of Chromatography, vol. 565, no. 1-2, pp. 237-246, 1991.

[33] N. K. Mathur and C. K. Narang, Determination of Organic Compounds with N-Bromosuccinamide and Allied Reagents, Academic Press, London, UK, 1975.
[34] G. A. Saleh, "Two selective spectrophotometric methods for the determination of amoxicillin and cefadroxil," Analyst, vol. 121, no. 5, pp. 641-645, 1996.

[35] I. H. Refaat, Contribution To the Analysis of Some Phenothiazines, Assiut University, Assiut, Egypt, 1983.

[36] P. Job, Advanced Physicochemical Experiments, Analytical Chemistry, Oliner and Boyd, 1964.

[37] H. Huang and H. Li, "Ultra-violet spectrophotometric determination of the content of nicardipine preparations," Yaowu Fenxi Zazhi, vol. 10, no. 6, pp. 359-360, 1990.

[38] K. Basavaiah, U. Chandrashekar, and H. C. Prameela, "Sensitive spectrophotometric determination of amlodipine and felodipine using iron(III) and ferricyanide," Farmaco, vol. 58, no. 2, pp. 141-148, 2003.

[39] D. C. Washington, The American Pharmaceutical Association, vol. 1, 31th edition, 2008.

[40] M. Haase, "Stability testing on vaccines: results of activities of the international conference on harmonization (ICH) of technical requirements for registration of pharmaceuticals for human use," Biologicals, vol. 22, no. 4, pp. 373-375, 1994.

[41] IUPAC, "Nomenclature, symbols, units and their usage in spectrochemical analysis. II. Data interpretation analytical chemistry division," Spectrochimica Acta B, vol. 33, p. 242, 1978.

[42] The British Pharmacopoeia, Majesty's Stationary Office, vol. 1, London, UK, 2009.

[43] The British Pharmacopoeia, Majesty's Stationary Office, vol. 2, London, UK, 2009. 

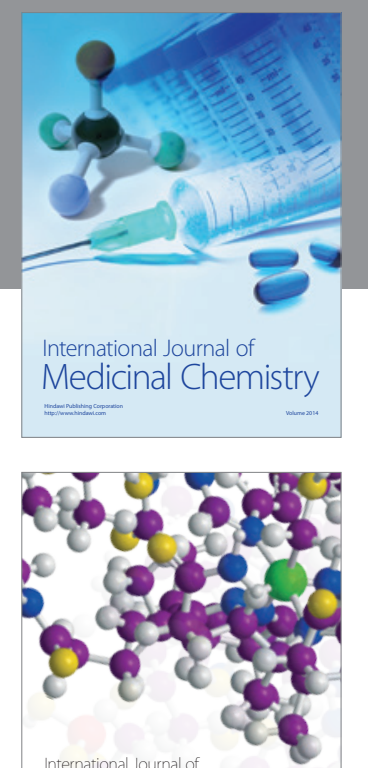

\section{Carbohydrate} Chemistry

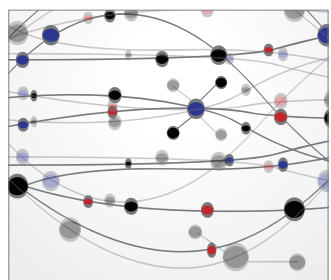

The Scientific World Journal
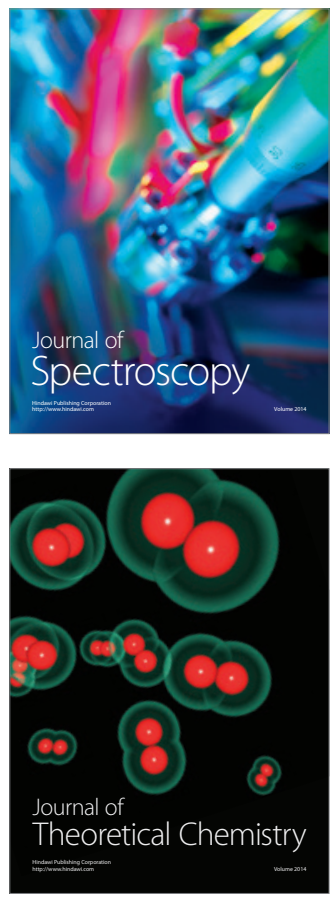
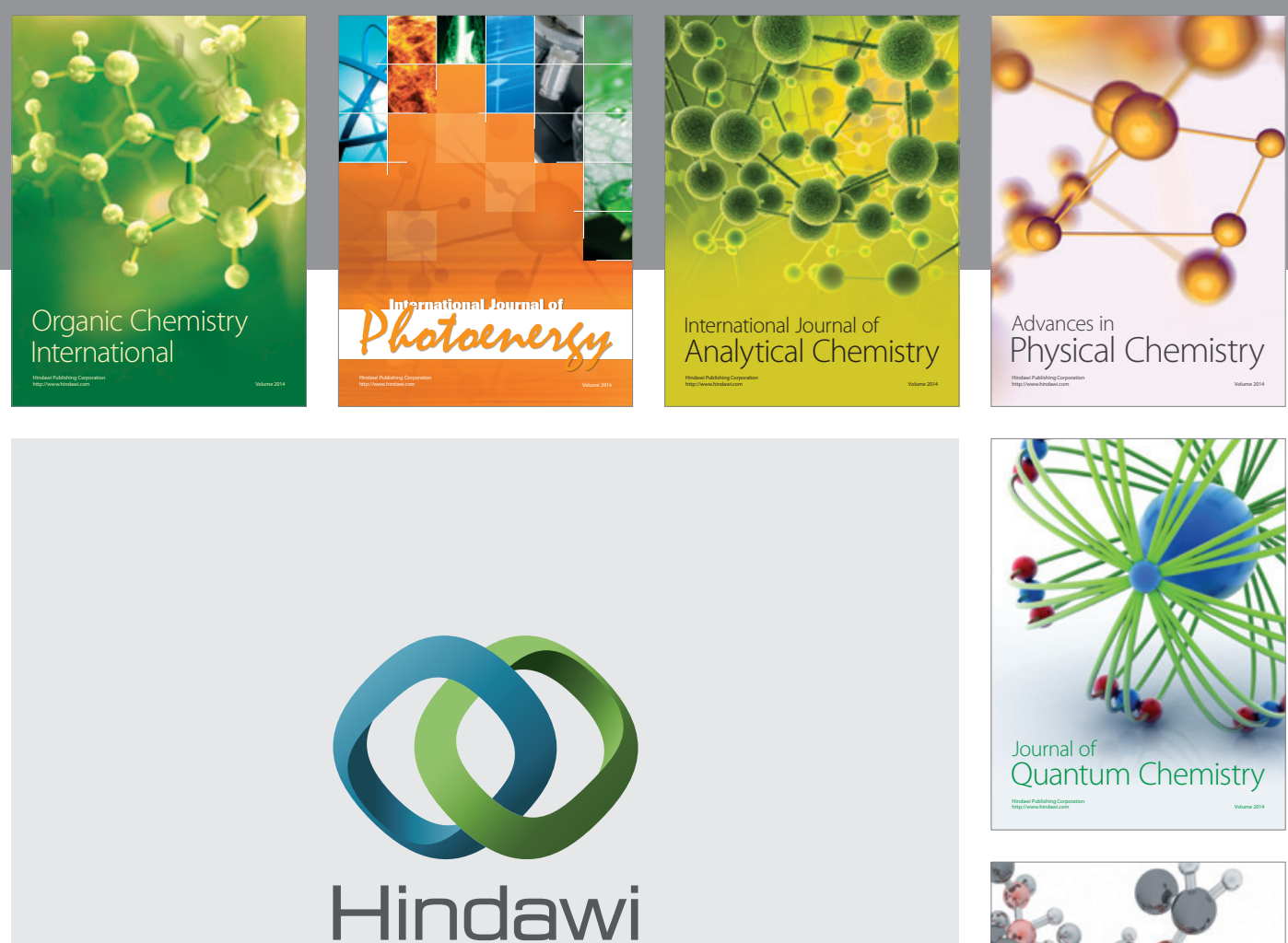

Submit your manuscripts at

http://www.hindawi.com

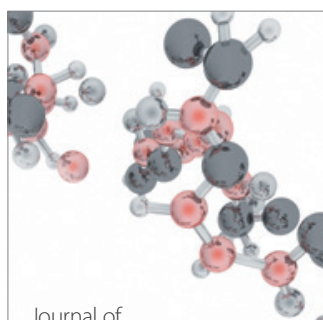

Analytical Methods

in Chemistry

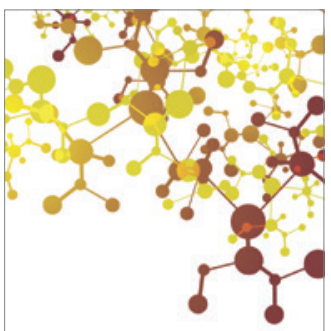

Journal of

Applied Chemistry

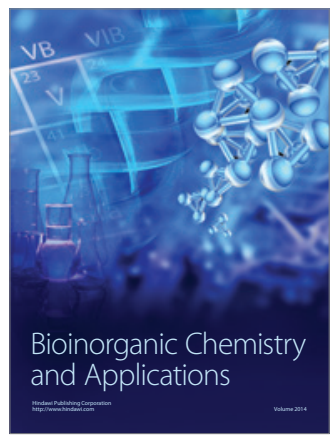

Inorganic Chemistry
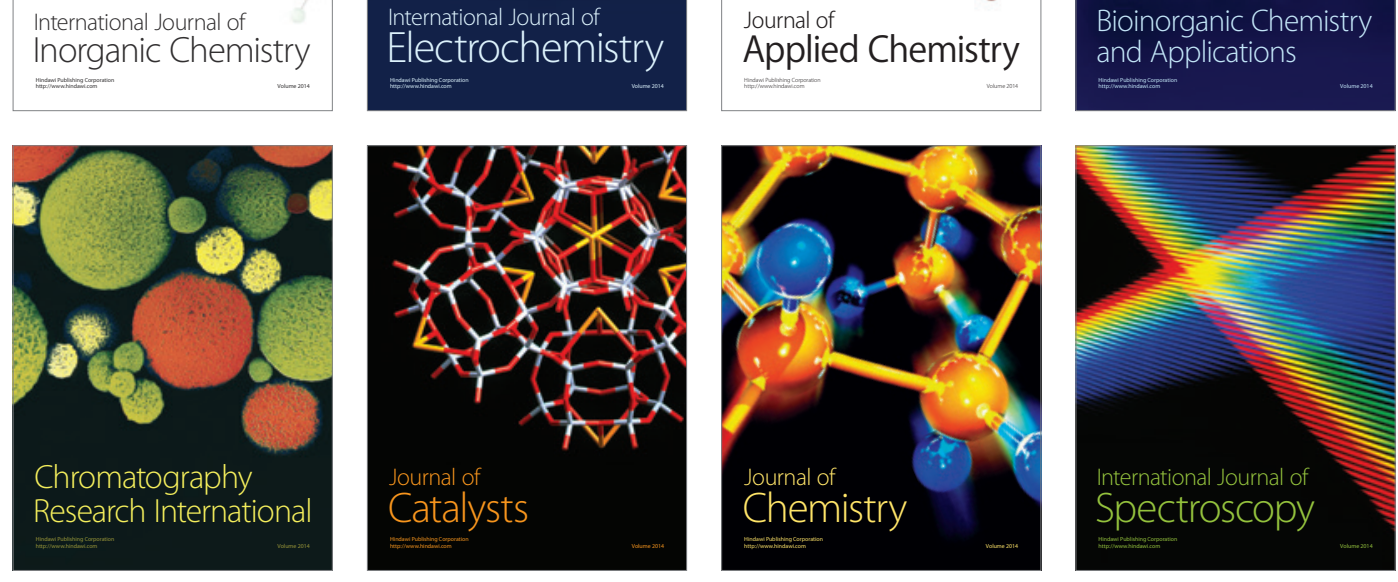